\title{
Awareness of Source of Radiation, Its Hazards and Protection among Final Year MBBS Students: A Cross-sectional Observational Study
}

DIPSA DIGANT SHASTRI ${ }^{1}$, NEHAL SANKET DIWANJI ${ }^{2}$, MONA DIGANT SHASTRI ${ }^{3}$, EKTA J DESAI ${ }^{4}$,

PARESH GORDHANBHAI PATEL ${ }^{5}$, NIRAV KISHORBHAI KADWANI ${ }^{6}$, NIPA PATIDAR $^{7}$, AVANI YOGESHBHAI BHATT ${ }^{8}$

(c) $)$ EY-NC-ND

\section{ABSTRACT}

Introduction: Increase availability of multi-detector high speed CT scan, digital radiography and various image guided interventional procedures has increased the total number of radiation related examinations in current era. These have lead to increase radiation exposure to patients as well as the radiologist. This situation has raised the concern about the potential side effects to patients, like radiation-related cancer and death.

Aim: Evaluation of awareness of source of radiation, radiation hazards and radiation protection among final year medical students in Tertiary Care Medical College Hospital.

Materials and Methods: This was a cross-sectional observational type of study in which total 136 final MBBS students were issued a questionnaire consisting of 12 multiple choice questions including demographic data, awareness about source of radiation, radiation hazard, protection issues and knowledge about radiation dose levels of common radiological examinations. All questions were multiple choice types with answers containing 2 to 9 choices having only one correct answer. The questionnaire was prepared by authors and their answers were validated by various faculties of Department of Radiodiagnosis by peer review methods. This questionnaire was given in a physical form. The obtained data were analysed using statistical software (descriptive statistics used). As homogenous group of final year medical students were analysed, no scoring and no statistical test were needed.

Results: In present study $87.5 \%(n=119)$ of students considered radiation knowledge important for them. Out of eight specific questions for checking their knowledge about radiation awareness, five questions were regarding safe radiation practice, radiation exposure, and radiation dose in common and radiological examination. Among these questions "Rule of 10"- question was correctly answered by $113(83.1 \%)$ of students. Questions regarding "Radiological examination of pregnant patient"- was correctly answered by 114 (83.8\%) of students and "Radiation exposure to patients during diagnostic radiology" question was correctly answered by 115 (84.6\%) of students.

Conclusion: Medical students have good awareness about radiation protection, with a specific gap of knowledge concerning source of radiation, biological effect of radiation and radiation hazards. Undergraduate teaching curriculum must include comprehensive knowledge about radiation hazards and radiation safety.

\section{INTRODUCTION}

$X$-rays and other medical imaging investigaions involve the use of ionizing radiation and are used daily in health care centres for diagnosis and management of various pathologies. Medical radiation to the general population is increasing, and is largely contributed by the increasing and widespread use of Computed Tomography (CT) [1]. Now many studies have shown that ionizing radiation at higher doses causes cell death and at low doses damage or alter the DNA of exposed cells $[1,2,3]$. In current era, medical imaging is a significant source of radiation exposure. The risk of radiation exposure from medical imaging is significant. In general, the effects of radiation vary according to the dose and duration of exposure and a linear, dose-dependent relationship model is commonly accepted for cancer development; and there is no threshold dose below which radiation exposure is safe [1]. Many studies have suggested that, medical practitioners who refer radiological examinations are unaware of the actual doses involved, possible risks to the health of patients, and as a result are unable to discuss the potential risks of radiological examinations with their patients $[1,2]$. Since many years in the postgraduate medical institute, it has been noticed that consultant and resident doctors have been prescribing radiological investigation like multiple $\mathrm{X}$-rays for medico-legal cases, barium studies, CT scan, inadvertently which leads to increase radiation exposure to patients. This can be avoided by safe investigation practice like replacing CT scan by Ultrasonography (USG) in paediatric patients where possible or by reducing number of $X$-rays. It has been decided to increase awareness among undergraduate students by assessing their present awareness about radiation and with result of this study, implement a proper teaching module at undergraduate level.

\section{MATERIALS AND METHODS}

A cross-sectional observational study involving homogenous group of final year MBBS students was conducted in Surat Municiple Institute of Medical Education and Research (SMIMER), which is a referral Tertiary Care Hospital in South Gujarat region of India. The study was first approved by the Institutional Ethics Committee and followed the standard ethical guidelines (SMIMER/IEC/OUT/NO.13). The study duration was from August 2019 to October 2019. A total of 150 students had appeared for final year preliminary examination conducted in the month of September 2019.

Inclusion criteria: Out of these 150, all students who gave consent to participate in the study were included in the study. 
Exclusion criteria: Students who were not willing to participate were excluded from study. Participants with incomplete questionnaire were excluded from the study.

Total 140 final year medical students gave consent for the study and participated in the study. Brief and easily understandable wellstructured questionnaire was prepared by the second and third author. All the questions were in the form of multiple choice questions format with 2-9 choices, one of which was the correct answer. First sections contain two questions for demographic data, age of the participants and sex. The second section contains third question, which was about their source of knowledge for radiation as they think. The third section contains fourth to twelfth (4-12) questions and was specific to their knowledge about source of radiation, radiation hazards, safe radiation practice, and radiological doses of common radiological investigation. The questions were selected from standard radiological book and other articles $[1,2,4,5]$. The answers were validated by three senior faculties of Department of Radiodiagnosis. A panel of three radiology faculties reviewed the questionnaire, Content Validity Index (CVI) was calculated for each question; average CVI was 0.89. To measure the test-retest reliability, the questionnaire was administered on seven radiology faculties within the interval of 11-21 days and the Intra-Class Correlation Coefficient (ICC) was calculated. The reliability of the questioner, as measured by internal consistency, was found to be satisfactory (Cronbach $\alpha=0.94)$. The results of test-retest reliability was $r=0.85, p<0.001$. After students had finished their prelim exam first author had distributed the printouts of questionnaire and explained in detail about the study [annexure]. The students were given total 15 minutes to complete the questionnaire and then the questionnaire were checked by authors of the study. However, due to incomplete questionnaire given by four students only 136 students were included finally in this study.

\section{STATISTICAL ANALYSIS}

Descriptive analysis used for representation of data. (Quantitative data represented by percentage).

\section{RESULTS}

Out of 136 participants, 72 were female and 64 were male and all belonging to age group between 20-25 years with mean age of 22.5 years and standard deviation 0.9116 . About $78 \%(n=106)$ of students mentioned tutorial for competitive exams as their source of information about radiation while rest $22 \%(n=30)$ mentioned reading books on radiation as a source of their knowledge. None of student mentioned undergraduate (UG) syllabus as their source of knowledge for questionnaire asked. Knowledge of ionising radiation dose in various radiological investigations is very much important to $87.5 \%$ $(n=119)$ of students, not important to $10.3 \%(n=13)$ students and $2.94 \%(n=4)$ students answered don't know. Both "not important" and "don't know" answers are considered as false response.

Regarding answer of biggest source of radiation in our daily life response was nuclear power plant by $13 \%(n=18)$, cosmic rays by $35.8 \%(n=49)$, diagnostic medical services at hospital $17.3 \%$ $(n=23)$, air travel $3.1 \%(n=4)$ rock and soil $8 \%(n=11)$, and microwave by $22.8 \%$ ( $n=31$ ) of students. Radon gas emitting from naturally occurring radioactive minerals in the ground, soil, and water is major cause of background radiation. This correct response was given by only $8 \%$ of students [Table/Fig-1]. Most worrisome sources of radiation exposure to human body is $\mathrm{X}$-ray and CT scan by $20.6 \%$ $(n=28)$, Radiotherapy by $27.2 \% \quad(n=37)$, nuclear weapons by $38.6 \%$ ( $n=52$, correct response), nuclear waste by $8 \%(n=11)$ and microwave by $5.6 \%(n=8)$ of students [Table/Fig-2]

Answer to health risk by radiation exposure was skin disorder by $13.9 \%(n=19)$, hair loss by $9.7 \%(n=13)$, cataract by $12.5 \%$ $(n=17)$, anaemia by $16.9 \%(n=23)$, infertility by $3.6 \%(n=5)$, Growth retardation by $2.9 \%(n=4)$, cancer by $13.9 \%(n=19)$, death by $9.5 \%$
Question 5 : According to you- the biggest source of radiation in our daily life - percentage of response
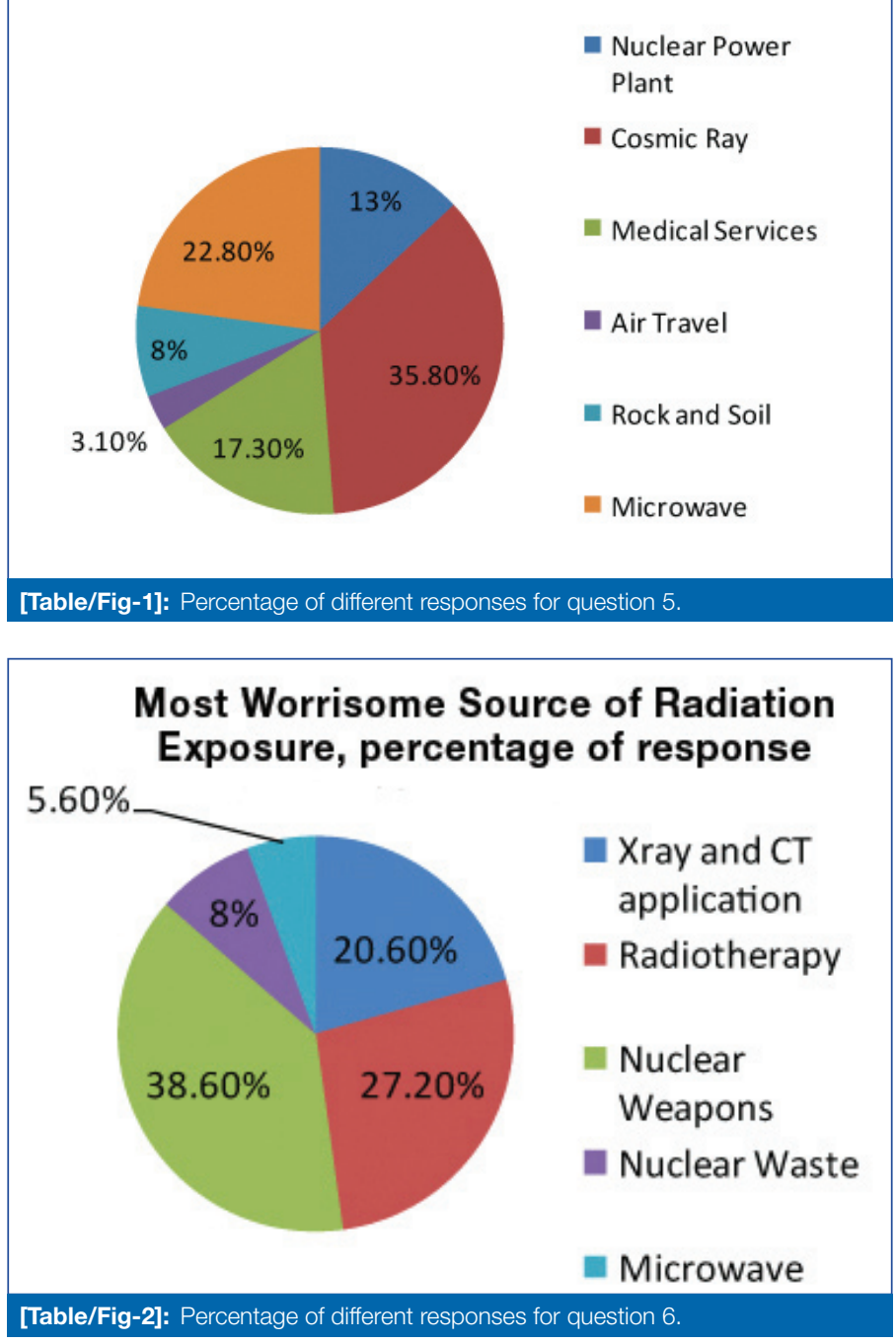

$(n=13)$ and all of the above by $17.1 \%(n=23$, correct response) [Table/Fig-3].

For rule of 10 about radiology examination, "to take X-ray during first ten days of menstrual cycle" is correct answer. About $83.1 \%$ $(n=113)$ students were correct about rule of 10 days while $16.9 \%$ $(n=23)$ students gave wrong answer. About 83.8\% $(n=114)$, answered that radiological examination of pregnant women can be performed with protective device to embryo, which is true answer while $16.2 \%(n=22)$ students were favoring never perform.

\section{Question 7: Health risk caused by radiation exposure, percentage of responses}

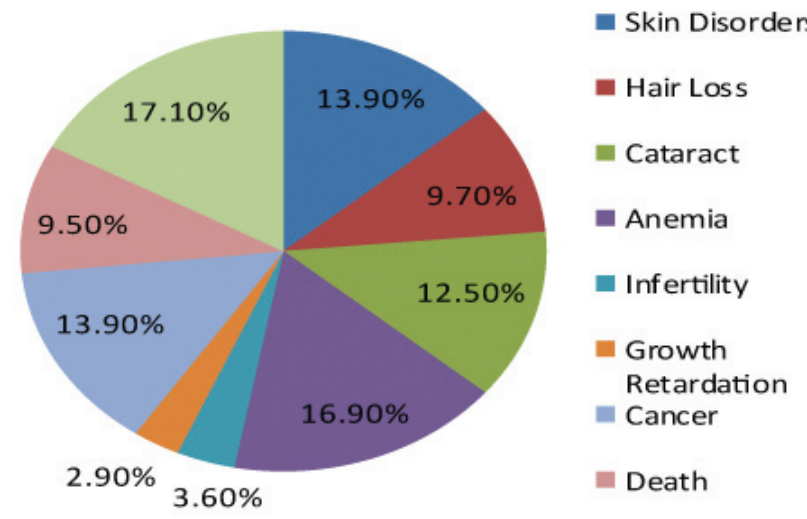

All of The Above

[Table/Fig-3]: Percentage of different response for question 7 . 
Answer to radiation exposure to patients during diagnostic radiology is not safe for both radiologist and patient was given by $84.6 \%$ $(n=115)$ of students and considered true, while $7.4 \%(n=10)$ believe that it is safe for radiologist but not for patients and $8.0 \%(n=11)$ students answered that it is safe for patient but not for radiologistboth this options as well as "safe" option is considered under false category.

Answer to what is approx radiation dose to humans during chest $X$-ray in $m S v$ was true by $63.2 \%(n=86)$ and wrong by $36.8 \%(n=50)$ students. About $91.2 \%(n=124)$ of students have given correct answer of no radiation exposure to human body during abdominal ultrasound and MRI, while $8.8 \%(n=12)$ students answered wrong.

\section{DISCUSSION}

Over the last several years, the undergraduate radiology curriculum in the institute has been formalised and integrated into the medical education curriculum, which places an emphasis on radiologic anatomy, introduction of various imaging modalities and basic image interpretation. However, given main importance to other major medical subjects radiology is always given least priority at undergraduate level. Further knowledge for radiation may be provided by books or tutorials for competitive exams. The aim of the work is to assess the degree of subjectively perceived knowledge and effective knowledge of essential radiation protection and dose assessment topics across a population of medical students. This will indirectly assess efficacy of the current curriculum. This study have included series of pre-validated well structured questions in such a way that they cover many aspect of radiation including source of radiation, hazards of radiation, safe radiation practice, and contraindication for the radiation examination and the dose of commonly done radiological investigation. The result of the study suggested the modification in the current medical curriculum to give necessary education of radiation hazards and radiation protection to future medical professional, which are going to prescribe these investigations the most.

In the past decade, several studies conducted in the world on selected cohorts of medical students, referring physicians, staff radiologists and technologists unveiled an alarming lack of radiation protection knowledge among them. But a few such types of studies are published in India [6-8]. Sukumar S et al., conducted an in depth an oral interview of 6 medical and dental practitioners in south India to assess their radiation awareness. The study highlighted the poor awareness among the medical doctors in India about the justification of practices, radiation and its hazards to pregnant woman and paediatric patient during the radiology examination [6]. Similar study conducted by Kokila BN et al., in south India including 185 undergraduate final year medical students, house surgeons and post-graduate students at a rural teaching medical institute located in southern India, gave similar result of low level of awareness on radiation dose and the risks associated with ionising imaging techniques. The study also demonstrated incremental increase in knowledge of radiation risk and protection from final year through internship and post graduation [7]. In one study conducted to assess the knowledge and practice of 215 medical professionals and nurses on radiation protection in interventional radiology, Iran showed lack of knowledge and practice concerning radiation protection concepts among medical professionals and nurses [8]. A study conducted in Norway for assessing awareness and knowledge of radiation dose and associated risks among 99 final year medical students concluded low level of knowledge of the students for radiation dose and risks associated with ionising radiation examination [9]. The study also showed that $27 \%$ and $15 \%$ of study population were unaware that MRI and ultrasound are non-ionising procedure. Similar study in Australia found that $11.3 \%$ and $25.5 \%$ of their students were unable to identify that ultrasound and MRI are non-ionising procedures [10]. Most of students in present study are aware about non-ionising nature of ultrasound and MRI and only $8.8 \%$ of students identify USG and MRI as ionising procedure. A study conducted by Faggioni $L$ et al., among 159 young doctors and students including 50 radiology residents, 56 medical students and 43 radiography students showed that study population have a limited awareness about radiation protection with a specific gap of knowledge about radiation dose of common radiological examination [3]. The present study showed similar result result that is, $36.8 \%$ students were unable to give correct answer of radiation dose during chest $\mathrm{X}$-ray study.

Compared to other past studies, students in this study have shown good knowledge about importance of radiation knowledge to them, rule of 10 in radiology, safe practice during pregnancy, safety of radiological investigation both for patient and doctor and radiation dose involved in USG and MRI. This may be partly contributed by their radiology knowledge given by tutorial for competitive exams as stated by $78 \%$ of students. So, this concludes that a proper practical knowledge to medical students can increase their radiation awareness. This also suggests that, the current radiology component of the undergraduate medical curriculum is widely ignored by students and not sufficient to contribute their basic radiation awareness knowledge. Radiation exposure during diagnostic radiology is similar to fire which has both beneficial as well as harmful effects [3]. Medical students must be aware of source of radiation, radiation hazards and radiation protection as they are future doctors who will prescribe radiological investigations for their patients [11-15]. Referring doctors should know about the risks and benefits of radiological investigations or procedures adviced in the management of a patient [16-20]. However, referring physcian pay little attention to or are unaware about radiation doses of common diagnostic investigations and therefore, they failed to explain patients about risks and benefits of a radiological test. This leads to unnecessary radiation exposure of patients and the community many times [21-23].

\section{Limitation(s)}

Limitation of present study is small sample size and homogenous group of students from one institute only.

\section{CONCLUSION(S)}

Adequate knowledge about radiation generating diagnostic equipment, hazardous effect of radiation and protective measures among medical students will establish safe work culture by minimising the radiation hazards to patients, public and radiation workers and maximising the benefits of study to patients. Thus, all medical colleges must include both theoretical as well as practical training about radiation protection in undergraduate medical curriculum.

\section{REFERENCES}

[1] Scali E, Mayo J, Nicolaou S, Kozoriz M, Chang S. Senior medical students' awareness of radiation risks from common diagnostic imaging examinations. Canadian Medical Education Journal. 2017;8(4):e3.

[2] Dellie ST, Admassie D, Ewnetu Y. An assessment of final-year medical students and intern's awareness of radiation exposure to common diagnostic imaging procedures. Advances in Radiology. 2014;2014:426909.

[3] Faggioni L, Paolicchi F, Bastiani L, Guido D, Caramella D. Awareness of radiation protection and dose levels of imaging procedures among medical students, radiography students, and radiology residents at an academic hospital: Results of a comprehensive survey. European Journal of Radiology. 2017;86:135-42.

[4] Thayalan K, textbook of Radiological Safety, Jaypee Brothers, Medical Publishers Pvt. Limited, 2009. ISBN, 8184488866.

[5] Day R. The "10-day rule". Radiology now. The British Journal of Radiology. 1974;47(555):198.

[6] Sukumar S, Rajagopal KV, Sabu KM. Perception of radiation awareness among medical doctors in India. International Journal of Pharmacy and Biological Sciences. 2013;3(3):371-76.

[7] Kokila BN, Shruthi Rai P, Darshan CL, Patel Parth N, Chitra. Awareness of radiation risks and protection among medical students: A cross-sectional study. International Journal of Scientific Research. 2019;8(3):42-43.

[8] Shafiee M, Rashidfar R, Abdolmohammadi J, Borzoueisileh S, Salehi Z, Dashtian $\mathrm{K}$. A study to assess the knowledge and practice of medical professionals on radiation protection in interventional radiology. The Indian Journal of Radiology \& Imaging. 2020;30(1):64. 
[9] Kada S. Awareness and knowledge of radiation dose and associated risks among final year medical students in Norway. Insights into Imaging. 2017:8(6):599-605

[10] Zhou GZ, Wong DD, Nguyen LK, Mendelson RM. Student and intern awareness of ionising radiation exposure from common diagnostic imaging procedures. Journal of Medical Imaging and Radiation Oncology. 2010;54(1):17-23.

[11] Mettler Jr FA, Bhargavan M, Faulkner K, Gilley DB, Gray JE, Ibbott GS, et al. Radiologic and nuclear medicine studies in the United States and worldwide: Frequency, radiation dose, and comparison with other radiation sources-19502007. Radiology. 2009;253(2):520-31.

[12] Smith-Bindman R, Lipson J, Marcus R, Kim KP, Mahesh M, Gould R, et al. Radiation dose associated with common computed tomography examinations and the associated lifetime attributable risk of cancer. Archives of Internal Medicine. 2009;169(22):2078-86.

[13] Miglioretti DL, Johnson E, Williams A, Greenlee RT, Weinmann S, Solberg LI, et al. The use of computed tomography in pediatrics and the associated radiation exposure and estimated cancer risk. JAMA Pediatrics. 2013;167(8):700-07

[14] Baysson H, Journy N, Roue T, Ducou-Lepointe H, Etard C, Bernier MO. Exposure to CT scans in childhood and long-term cancer risk: A review of epidemiological studies. Bulletin du Cancer. 2016;103(2):190-98.

[15] Mathews JD, Forsythe AV, Brady Z, Butler MW, Goergen SK, Byrnes GB, et al. Cancer risk in 680000 people exposed to computed tomography scans in childhood or adolescence: Data linkage study of 11 million Australians. BMJ. 2013; 21;346.
[16] Kuefner MA, Brand M, Engert C, Schwab SA, Uder M. Radiation induced DNA double-strand breaks in radiology. InRöFo-Fortschritte auf dem Gebiet der Röntgenstrahlen und der bildgebenden Verfahren 2015;187(10):872-78. C Georg Thieme Verlag KG.

117] Kanagaraj K, Basheerudeen SA, Jose MT, Ozhimuthu A, Pattan S, Perumal V. Assessment of dose and DNA damages in individuals exposed to low dose and low dose rate ionising radiations during computed tomography imaging. Mutation Research/Genetic Toxicology and Environmental Mutagenesis. 2015;789:01-06.

[18] Shaw PV, Croüail P, Paynter R, Coeck M. Education and training in radiation protection: Improving ALARA culture. Journal of Radiological Protection. 2015;35(1):223

[19] Günalp M, Gülünay B, Polat O, Demirkan A, Gürler S, AkkaşM, et al. lonising radiation awareness among resident doctors, interns, and radiographers in a university hospital emergency department. La Radiologia Medica. 2014;119(6):440-47.

[20] Lee RK, Chu WC, Graham CA, Rainer TH, Ahuja AT. Knowledge of radiation exposure in common radiological investigations: a comparison between radiologists and non-radiologists. Emergency Medicine Journal. 2012;29(4):306-08.

[21] Cole P, Hallard R, Broughton J, Coates R, Croft J, Davies K, et al. Developing the radiation protection safety culture in the UK. Journal of Radiological Protection. 2014;34(2):469.

[22] Coldwell T, Cole P, Edwards C, Makepeace J, Murdock C, Odams H, et al. The advantages of creating a positive radiation safety culture in the higher education and research sectors. Journal of Radiological Protection. 2015;35(4):917.

[23] Singh RK, McCoubrie P, Burney K, Miles JA. Teaching medical students about radiation protection- what do they need to know? Clin Radiol. 2008;63(12):1344-49.

\section{PARTICULARS OF CONTRIBUTORS:}

1. Internship, Department of Radiodiagnosis, Surat Municipal Institute of Medical Education and Research, Surat, Gujarat, India.

2. Associate Professor, Department of Radiodiagnosis, Surat Municipal Institute of Medical Education and Research, Surat, Gujarat, India.

3. Professor, Department of Radiodiagnosis, Surat Municipal Institute of Medical Education and Research, Surat, Gujarat, India.

4. Associate Professor, Department of Radiodiagnosis, Surat Municipal Institute of Medical Education and Research, Surat, Gujarat, India.

5. Assistant Professor, Department of Radiodiagnosis, Surat Municipal Institute of Medical Education and Research, Surat, Gujarat, India

6. Tutor, Department of Radiodiagnosis, Surat Municipal Institute of Medical Education and Research, Surat, Gujarat, India.

7. Assistant Professor, Department of Radiodiagnosis, Surat Municipal Institute of Medical Education and Research, Surat, Gujarat, India.

8. Tutor, Department of Radiodiagnosis, Surat Municipal Institute of Medical Education and Research, Surat, Gujarat, India.

\section{NAME, ADDRESS, E-MAIL ID OF THE CORRESPONDING AUTHOR}

Nehal Sanket Diwanji,

702, Wilson Tower, Behaind Agrwal Samaj Bhavan, GHOD DOD Road,

Surat, Gujarat, India.

E-mail: nehaldiwanji@yahoo.co.in
PLAGIARISM CHECKING METHODS: [Jain Het al.]

- Plagiarism X-checker: May 06, 2020

- Manual Googling: Oct 06, 2020

- iThenticate Software: Jan 27, 2021 (20\%)
ETYMOLOGY: Author Origin

\section{AUTHOR DECLARATION:}

- Financial or Other Competing Interests: None

- Was Ethics Committee Approval obtained for this study? Yes

- Was informed consent obtained from the subjects involved in the study? Yes

- For any images presented appropriate consent has been obtained from the subjects. NA
Date of Submission: May 05, 2020 Date of Peer Review: Jun 22, 2020 Date of Acceptance: Oct 06, 2020 Date of Publishing: Apr 01, 2021

\section{Appendix:}

Department of Radiodiagnosis, SMIMER Hospital, Surat, Gujarat, India

Survey for awareness of radiation hazards in Final MBBS students Questionnaire study.

Please tick most appropriate answer.

1) Age

20-25 years

25-30 years

2) Gender

Male

Female

3) Your source of information about Radiation

UG Syllabus

Reading books on Radiation

Tutorials for competitive exams

4) How important do you think, knowledge of ionising radiation dose of common radiological investigation in routine medical practice-

Not really important

Very important

Moderately important

Don't know
5) According to you- The biggest source of radiation in our daily life Nuclear Power plant

Cosmic Ray

Medical services at hospital

Air travel

Rock and Soil

Microwave

6) Most worrisome sources of radiation exposure

X-ray and CT Application

Radiotherapy

Nuclear weapons

Nuclear waste

Microwave

7) Health risk caused by radiation exposure

Skin Disorders

Hair loss

Cataract

Anaemia

Infertility

Growth retardation

Cancer

Death

All of the above 
8) Rule of 10 days is-

To take $\mathrm{X}$-ray during first 10 days of pregnancy

To take $\mathrm{X}$-ray during first 10 days of menstrual cycle

9) Radiological exam of pregnant patient -

Never perform

Perform, if justified by doctor

Perform with protective device for embryo

10) Radiation exposure to patient during diagnostic radiology is

Safe for Patient but not for doctor

Safe for Doctor but not for patient

Safe for both

Not safe
11) What is approx. radiation dose to patient during Chest xray exam (mSv)

0.02

0.2

2

20

12) Radiation dose in mSv to human body during abdominal ultrasound (mSv)

0.1

0.2

0.0

0.005 